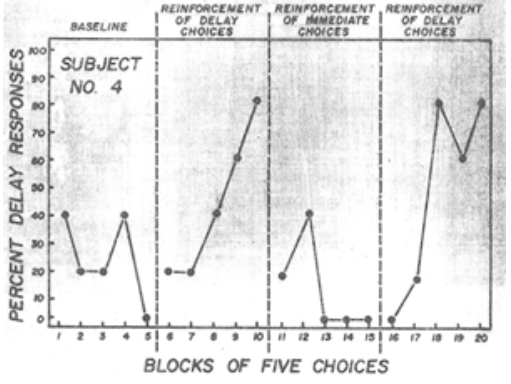

Fig. 4. Per cent delay responses as a function of phases of the experiment for the fourth $S$.

contingencies operating in this experiment. However, no claim for "learning without awareness" is made since no detailed postconditioning interview (e.g., Speilberger, 1962) was conducted.

Thus far, two behavior modification regimes have resulted in control of delaying behavior in these inmates: exposure to high-delay peer models (Stumphauzer, in press) and the present study using social reinforcement. It is suggested that a behavior-modification program aimed at increased delay of gratification in delinquents and youthful offenders would require repeated modeling of high-delay behavior by several models in a number of different situations. Further, social reinforcement, other more extrinsic reinforcers, and scheduling variables might be manipulated to achieve the generalized delay of gratification.

\section{REFERENCES}

BANDURA, A., \& MISCHEL, W. Modification of self-imposed dclay of reward through exposure to live and symbolic models. Joumal of Personality \& Social Psychology, 1965, 2, 298-705.

GEWIRTZ, J. L., \& BAER, D. M. The effect of brief social deprivation on behaviors for a social reinforcer. Journal of Abnormal \& Social Psychology, 1958, 56, 49-56.

MISCHEL, W. Preference for delayed reinforcement and social responsibility. Journal of Abnormal \& Social Psychology, $1961,62,1-7$

SPIELBERGER, C. D. The role of awareness in verbal conditioning. In C. W. Eriksen (Ed.), Behavior and awareness. Durham: Duke University Press, 1962. Pp. 73-101.

STUMPHAUZER, J. S. Application of reinforcement contingencies with a 23-year-old anorexic patient. Psychological Reports, 1969, $24,109-110$.

STUMPHAUZER, J. S. Increased delay of gratification in four youthful offenders through exposure to a model. Crime \& Delinquency Abstracts, in press.

$$
\text { NOTES }
$$

1. Based on a paper read at Florida Psychological Association, Orlando, May 3, 1969.

2. Now with the Department of Psychology, University of Southern California Medical Center, 1934 Hospital Place, Los Angeles, California 90033.

\title{
Selective attention to pure tones and speech
}

\section{NEVILLE MORAY and MARY FEE, University of Sheffield, Sheffield, England}

An experiment by Lawson (1966) has been repeated with more adequate controls. Contrary to her findings, listeners make more errors in responding to pure tones in speech messages when they occur in a rejected than in an accepted dichotic message, and the most common errors are omissions. This reopens the question as to whether or not verbal and nonverbal signals are treated differently when selectively processed by the brain.

An experiment by Lawson (1966) has played an important role in the theory of selective attention due to Treisman (Treisman \& Geffen, 1967; Treisman, 1967), which maintains that undesired messages are "attenuated" early in the nervous system in such a way that their verbal content becomes relatively inaccessible to the listener. On the other hand, their physical characteristics are accessible (pitch, loudness, spatial position, etc.), implying that these are analyzed before the "attenuator." Lawson found that if pure tones were embedded in speech and the listener was required to respond to them by pressing one key if a pure tone arrived in the rejected message and another key if it arrived in the accepted message while repeating aloud the accepted message, then no pure tones were missed from either message, a result that supports Treisman's model. What few errors occurred were false alarms.

However, the following information is not given in Lawson's paper: whether the tone bursts used had a slow or fast rise time, the relative and absolute intensity of speech and tone bursts, and the speech rate of the verbal message. Hence, there might be several reasons for the high detectability of the tone signals, such as the presence of switching transients, cross talk between the cars, or bad intensity mismatch of speech and tone. The speech passage was very long, and the tone bursts added to the speech, so that even if they had been of equal intensity to the speech, occurrence of the tone burst would have increased the acoustic energy in the critical band centered on $750 \mathrm{~Hz}$ (Lawson's frequency) by $6 \mathrm{~dB}$. The present experiment was, therefore, performed to check Lawson's results.

\section{METHOD}

The basic design was a copy of Lawson's with the following alterations and explicit values. Speech rate $=120$ words per minute. Passage length $=240$ words. One message was presented to each ear, and each message contained five tone bursts per message, randomly placed but with no two bursts occurring simultaneously on the two channels. Speech SPL = approximately $50 \mathrm{~dB}$ per channel re 0.0002 dynes $/ \mathrm{cm}^{2}$. Tone-burst duration was $350 \mathrm{msec}$, at $750 \mathrm{~Hz}$. The rise time of the tone bursts was either $1 \mathrm{msec}$ or $50 \mathrm{msec}$, and their intensity relative to the speech average intensity was $-10,-5,0,+5$, or $+10 \mathrm{~dB}$. Presentation order was balanced for which passages were rejected or accepted, order of intensity conditions, and order of rise time conditions. Twenty listeners were used, all of them students. The listeners repeated one of the messages and responded to the occurrence of tones by pressing a left-hand key for a left-ear tone and a right-hand key for a rightear tone. Unlike Lawson's experiment, the speech in a message was turned off when a tone sounded in that message and turned on again when the tone ceased, by means of a Grason-Stadler electronic switch.

\section{RESULTS}

One $\mathrm{S}$ was dropped from the analysis because of a very high rate of error in his detection of both accepted and rejected ear tone bursts; his qualitative pattern of resuits was similar to those of the remaining 19 Ss. (Note that he violates Lawson's claim that Ss show no omissions.) The pooled data of the $S s$ is shown in Table 1. Notice that (1) there are twice as many rejected message errors as there are accepted message errors, and (2) these are mainly omissions. These findings contradict Lawson's. Analysis of variance showed that the rejected/accepted channel error difference was significant at better than the 0.01 level of probability. The main effects due to rise time and intensity ratio of tone to speech were not significant sources of variance, but there was a significant interaction of rise time with intensity $(\mathrm{p}<0.01)$. 
Table I

Total Number of Each Type of Error Under Each Condition for Shadowed and Rejected Channels

\begin{tabular}{|c|c|c|c|c|c|c|c|c|c|c|c|c|c|c|c|c|c|c|c|c|}
\hline \multirow{2}{*}{$\begin{array}{l}\mathrm{dB} \\
\text { Channel }\end{array}$} & \multicolumn{2}{|c|}{+10} & \multicolumn{2}{|c|}{+5} & \multicolumn{2}{|c|}{+0} & \multicolumn{2}{|c|}{-5} & \multicolumn{2}{|c|}{-10} & \multicolumn{2}{|c|}{+10} & \multicolumn{2}{|c|}{+5} & \multicolumn{2}{|c|}{+0} & \multicolumn{2}{|c|}{-5} & \multicolumn{2}{|c|}{-10} \\
\hline & $\mathrm{S}$ & $\mathbf{R}$ & $\mathrm{S}$ & $\mathbf{R}$ & $\mathrm{S}$ & $\mathbf{R}$ & $\mathrm{S}$ & $\mathbf{R}$ & $\mathrm{S}$ & $\mathrm{R}$ & $S$ & $\mathrm{R}$ & $\mathrm{S}$ & $\mathbf{R}$ & $S$ & $\mathrm{R}$ & $S$ & $\mathrm{R}$ & $\mathrm{S}$ & $\mathbf{R}$ \\
\hline Omissions & 3 & 10 & 3 & 12 & 2 & 11 & 6 & 9 & 2 & 8 & 3 & 4 & 3 & 5 & 3 & 10 & 4 & 13 & 5 & 8 \\
\hline False Positives & 1 & 0 & 1 & 1 & 0 & 1 & 2 & 1 & 2 & 1 & 0 & 1 & 1 & 2 & 0 & 0 & 5 & 1 & 1 & 4 \\
\hline Wrong Channel & 1 & 0 & 3 & 1 & 1 & 1 & 0 & 0 & 1 & 0 & 0 & 1 & 1 & 1 & 1 & 1 & 0 & 0 & 2 & 1 \\
\hline Both Channels & 2 & 3 & 0 & $\tilde{1}$ & 1 & 0 & 0 & 2 & 0 & 0 & 0 & 2 & 0 & 2 & 0 & 2 & 3 & 2 & 2 & 3 \\
\hline Total $\begin{array}{l}\text { Shadowed } \\
\text { Rejected }\end{array}$ & 7 & 13 & 7 & 15 & 4 & 13 & 7 & 11 & 5 & 9 & 3 & 8 & 5 & 10 & 4 & 13 & 12 & 16 & 10 & 16 \\
\hline Total $($ Sh + Rej $)$ & & & & & & & & & & & & & & & & & & & & \\
\hline
\end{tabular}

\section{DISCUSSION}

These results clearly differ from those of Lawson and cast doubt on the claim that physical characteristics of incoming rejected messages are not handled by the selection mechanisms in a way similar to the way in which speech is handled. The decrease in performance is not as great as with verbal signals but is, nonetheless, considerable. There are at least six possible sources of the difference. Some have already been indicated in the introduction: The tone bursts may have been very much louder than the speech and may have produced crosstalk to the opposite ear; switching transients may similarly have produced crosstalk even though the main signals did not. The shadowing task may have been easier. In addition, nearly half of our Ss produced the same results as Lawson's, and showed virtually no errors. It therefore appears that there are at least two groups of Ss between which there is a marked individual difference, and this makes any straight-forward interpretation of the data difficult.

However, it might be said that the results are closer to Lawson's than to speech data. For example, Treisman \& Geffen (1967) found a mean omissions rate for a manual response to target words of $18.1 \%$ in the accepted channel and $93.1 \%$ in the rejected channel (calculated from data given in their paper). In our experiment, the corresponding omissions were $3.4 \%$ and $9.0 \%$. When the target words were spoken in a different voice from the background message. Treisman (1967) found omission rates of 3\% for accepted message words and 3\% from rejected message words. The differences in these studies clearly have something to do with the way in which tones differ from speech or different voices from one another. Lawson argued that her results showed that separate pathways exist for physical and verbal stimuli, and that the pathways for physical stimuli are constantly monitored even in the case of a rejected message. The fact that even a low omisșion rate is found in our study argues against this. Also, Lawson found that when the pitch discrimination task was made more difficult, performance on the rejected channel did, in fact, become impaired before repetition of the accepted channel did. As Lindsay (1967) points out, discrimination of pitch or intensity of pure tones require capacity just as does the analysis of semantic content. He suggests that difficulty of discriminability between signals and limits on storage capacity may be the crucial factors in such tasks. In both Lawson's and the present experiment, it seems likely that these two factors will be optimal: Tones are readily discriminable from speech, and there was no storage required, but an immediate response. Ease of discrimination would also be greater than in early experiments in the case of
Treisman's experiment using two voices.

Such considerations would lead more naturally to a model in which the selective mechanism is sensitive to sudden changes in the statistical properties of all incoming messages [such as Broadbent (1958) suggested many years ago] and to a model based on running correlation of input rather than to a dual system that handles verbal and nonverbal messages differently. At the very least, bearing in mind the present results and those of Moray (in press) on the psyphophysics of attention, Lawson's results cannot be taken to establish the existence of her proposed dual mechanisms.

\section{REFERENCES}

BROADBENT, D. Perception and communication. London: Pergamon Press, 1968.

LAWSON, E. Decisions concerning the rejected channel. Quarterly Journal of Experimental Psychology, 1966, 18, 260-265.

MORAY, N. Introductory experiments in auditory time-sharing: The detection of intensity and frequency increments. Journal of the Acoustical Society of America. in press.

TREISMAN, A. "Selective attention: Stimulus or response?": A reply. Quarterly Journal of Experimental Psychology, 1967, 19, 362-368. TREISMAN, A., \& GEFFEN, G. Selective attention: Perception or response? Quarterly Journal of Experimental Psychology, 1967, 19, 1-18. 